\title{
Nanopartículas de prata: método alternativo de sanitização para couve minimamente processada ${ }^{1}$
}

\author{
Emiliane Andrade Araújo ${ }^{2}$, Flávia Regina Passos ${ }^{3}$, \\ Lorena Ribeiro ${ }^{3}$, Adayane Aparecida Pereira ${ }^{3}$, José Felício Queiroz Fialho Júnior ${ }^{4}$
}

\begin{abstract}
Silver nanoparticles: an alternative method for sanitization of minimally processed cabbage

The minimal processing of vegetables basically aims to extend food shelf life, which depends on a number of factors, such as sanitization, that is considered a critical step for food microbiological quality. However, the usual antimicrobial agents reduce the microbial population in a maximum of two logarithmic cycles. Therefore, it is necessary to develop alternative sanitizers. This study aimed to increase the innocuity of minimally processed cabbage through sanitization with silver nanoparticles. It was observed that the nanoparticles promoted three logarithmic reductions, i.e. a $99.9 \%$ reduction rate, in the Escherichia coli population inoculated on the cabbage surface. When compared to other antimicrobial agents (sodium dichloroisocyanurate and sodium hypochlorite), the nanoparticles were more efficient in sanitizing minimally processed cabbage, showing a lower count of aerobic mesophils. It was also observed that the cabbage surface presents hydrophobic characteristics, resulting in a higher propension for bacterial adhesion, which was confirmed in the thermodynamic evaluation of favorable adhesion for Staphylococcus aureus, Escherichia coli and Listeria innocua.
\end{abstract}

KEY-WORDS: Brassica oleracea L.; antimicrobial agents; hydrophobicity.

\section{INTRODUÇÃO}

O mercado de alimentos minimamente processados é cada vez mais popular, por assemelharem-se a produtos frescos e que possuem maior padronização, conveniência e praticidade. No Brasil, diversos são os produtos potencialmente utilizáveis como minimamente processados, destacando-se a alface, brócolis, cenoura, repolho e couve. Essa última é altamente

\section{RESUMO}

\begin{abstract}
O processamento mínimo de hortaliças visa, basicamente, a estender a vida útil dos alimentos, o que depende de uma série de fatores, como, por exemplo, a sanitização, a qual é considerada etapa fundamental para a qualidade microbiológica do alimento. No entanto, os agentes antimicrobianos usuais reduzem a população microbiana em, no máximo, dois ciclos logarítmicos. Dessa forma, existe a necessidade de desenvolvimento de sanitizantes alternativos. O presente trabalho objetivou aumentar a inocuidade de couve minimamente processada, por meio de sanitização com nanopartículas de prata. Observou-se que as nanopartículas promoveram três reduções logarítmicas, ou seja, 99,9 \% de redução, na população de Escherichia coli inoculada na superfície da couve. Quando comparadas com outros agentes antimicrobianos (dicloroisocianurato de sódio e hipoclorito de sódio), as nanopartículas mostraram-se mais eficientes na sanitização da couve minimamente processada, apresentando menor contagem de mesófilos aeróbios. Observou-se, também, que a superfície da couve apresenta características hidrofóbicas, resultando em maior propensão para adesão bacteriana, o que foi confirmado na avaliação da termodinâmica de adesão favorável para Staphylococcus aureus, Escherichia coli e Listeria innocua.
\end{abstract}

PALAVRAS-CHAVE: Brassica oleracea L.; agentes antimicrobianos; hidrofobicidade.

consumida pela população brasileira, o que viabiliza o seu uso como alimento minimamente processado (Heimler et al. 2007).

Produtos minimamente processados podem aumentar o risco de surtos de doenças transmitidas por alimentos, devido ao fato de que a cadeia de produção causa injúrias ou ferimentos e, por conseguinte, aumenta a taxa de senescência de tecidos e reduz a sua resistência à deterioração microbiana (Moretti 2002,

1. Trabalho recebido em jun./2014 e aceito para publicação em mar./2015 (http://dx.doi.org/10.1590/1983-40632015v4530551).

2. Universidade Federal do Triângulo Mineiro (UFTM), Departamento de Engenharia de Alimentos, Uberaba, MG, Brasil. E-mail: emilianeandrade@yahoo.com.br.

3. Universidade Federal de Viçosa (UFV), Instituto de Ciências Agrárias, Rio Paranaíba, MG, Brasil. E-mails: flaviapassos1@yahoo.com.br, lorena.r.ribeiro@ufv.br, adayane.pereira@ufv.br.

4. Universidade Federal de Viçosa (UFV), Departamento de Ciência e Tecnologia de Alimentos, Viçosa, MG, Brasil. E-mail: juniorqf@gmail.com. 
Artés et al. 2007). A lavagem com agentes sanitizantes é a única etapa que reduz a carga microbiana antes do armazenamento (Gómez-López et al. 2005). Os patógenos mais envolvidos nos surtos são Listeria monocytogenes, Salmonella e Escherichia coli, bem como alguns tipos de vírus e protozoários (Abadias et al. 2008).

Focos de contaminação na superfície dos alimentos podem propiciar a adesão microbiana e, consequentemente, a formação de biofilmes. Existem, na literatura, dados de experimentos que mostram que a adesão microbiana depende fortemente da estrutura hidrofóbica e/ou hidrofílica das superfícies de interação. A importância do caráter hidrofóbico da superfície das células na adesão foi explicada por Van Loosdrecht et al. (1990). Para que seja estabelecida uma adesão efetiva entre duas superfícies, em meio aquoso, o filme de água que as separa tem que ser removido, e a hidrofobicidade das superfícies interatuantes contribui para a facilidade dessa remoção. Portanto, a interface bactéria e líquido e a interface superfície de adesão e líquido terão que ser substituídas pela interface bactéria e superfície de adesão. Segundo a teoria termodinâmica, a adesão só se verifica se o processo conduzir a uma redução da energia livre global, obtendo-se valores negativos de $\Delta \mathrm{G}_{\text {adesão }}$

Como as hortaliças minimamente processadas são produtos prontos para o consumo, essas devem estar livres de patógenos e com número reduzido de deterioradores. Assim, torna-se necessário que cada etapa do processamento desses vegetais seja feita com água de boa qualidade e com a adição de soluções sanitizantes. O uso dessas soluções reduz significativamente a contaminação, resultando na obtenção de produtos microbiologicamente mais seguros. Portanto, a sanitização tem importante papel na minimização da deterioração e na manutenção da qualidade do produto (Srebernich 2007).

A remoção de micro-organismos pode ser dificultada dependendo do tipo de hortaliça considerada, uma vez que alguns tecidos vegetais podem apresentar fissuras e espaços intercelulares, que podem proteger as células bacterianas, dificultando o acesso do agente antimicrobiano (Moretti 2007). Dessa forma, surge a necessidade de desenvolvimento de sanitizantes alternativos, destacando-se, dentre eles, as nanopartículas de prata.

As nanopartículas de prata são relativamente inovadoras e apresentam amplo espectro de ação contra bactérias gram-positivas e gram-negativas, fungos filamentosos, leveduras e vírus. As nanopartículas de prata também possuem grande área interfacial, o que poderá resultar em maior eficiência para penetração em fissuras celulares. Em relação à toxicidade para as células animais, a prata é o metal que apresenta a menor toxicidade (Berni Neto et al. 2008).

O mecanismo de ação antimicrobiana proposto para as nanopartículas de prata refere-se à interação com grupos que contêm os elementos enxofre e fósforo, que são encontrados tanto nas membranas celulares como no citoplasma das bactérias. Sua interação ocorre com a membrana celular, causando danos ao processo de respiração celular, e, no interior das células, interagem com o DNA, impedindo a divisão celular (Morones et al. 2005).

Nesse contexto, este trabalho objetivou avaliar a atividade antimicrobiana de nanopartículas de prata na sanitização de couve minimamente processada, bem como determinar a hidrofobicidade, para predizer sobre a termodinâmica de adesão de diferentes espécies bacterianas, em superfícies de couve minimamente processadas.

\section{MATERIAL E MÉTODOS}

Os experimentos microbiológicos foram conduzidos no Laboratório de Microbiologia da Universidade Federal de Viçosa, em Rio Paranaíba (MG), no ano de 2011. As amostras de couve foram adquiridas no comércio local da cidade e transportadas sob refrigeração para o laboratório. As análises físico-químicas foram realizadas no Laboratório de Higiene Industrial da Universidade Federal de Viçosa.

A dispersão de nanopartículas de prata foi preparada a partir de uma mistura de solução aquosa de surfactante dodeciltrimetilamônio (Dotab) (Sigma, São Paulo, Brasil) duas vezes mais concentrado $(0,0312 \mathrm{M})$ que a concentração micelar crítica (CMC) e de sulfadiazina de prata (SAg), na concentração de $0,028 \mathrm{M}$ (Sigma, São Paulo, Brasil). A dispersão foi submetida a uma agitação suficiente para garantir mistura completa e, em seguida, realizou-se centrifugação da dispersão a $15.000 \mathrm{~g}$, por 5 minutos, em centrífuga. O sobrenadante de coloração amarela obtida com as nanopartículas foi separado do pellet e utilizado nas análises microbiológicas. As nanopartículas de prata concentradas foram obtidas pela mesma metodologia, sendo, após a separação do pellet, submetidas a aquecimento, para evaporação parcial (70 \%) do solvente, a fim de concentrar as nanopartículas presentes na dispersão. 
Após a recepção no laboratório de microbiologia, as couves foram armazenadas em câmara fria $\left(5^{\circ} \mathrm{C}\right)$, com o objetivo de reduzir o seu metabolismo, para posterior seleção. As hortaliças foram lavadas em água corrente potável, com concentração de cloro residual total de $1 \mathrm{ppm}$, por, aproximadamente, 3 minutos. O corte foi realizado com o auxílio de uma lâmina de corte de $1 \mathrm{~mm}$, gerando fatias de couve com espessuras de 1-3 mm. A primeira lavagem foi realizada por meio da imersão das fatias de couve em água potável, resfriada a $5{ }^{\circ} \mathrm{C}$, por 5 minutos, para remover o fluído celular e vascular presentes nas extremidades cortadas, ricos em nutrientes e que auxiliam na multiplicação da carga microbiana inicial. Na segunda lavagem, os cortes foram sanitizados conforme as concentrações apresentadas na Tabela 1, por 15 minutos.

Para remover o excesso de sanitizante, realizou-se o enxágue da couve minimamente processada em água resfriada a $5{ }^{\circ} \mathrm{C}$, por 5 minutos, contendo 5 ppm de hipoclorito de sódio. Os produtos foram drenados, colocados em sacos de náilon e centrifugados por 1 minuto, utilizando-se centrífuga doméstica (Arno) de pequeno porte, com velocidade constante de $800 \mathrm{~g}$.

A couve minimamente processada foi acondicionada, separadamente, em embalagem de polietileno expandido (bandeja) revestida com filme de policloreto de vinila (PVC). Cada embalagem continha $25 \mathrm{~g}$ de couve minimamente processada. $\mathrm{O}$ armazenamento das amostras foi efetuado à temperatura de $5{ }^{\circ} \mathrm{C}$, durante 10 dias.

A tensão interfacial das soluções de sanitizantes foi avaliada com o uso de goniômetro (Easy Drop, Krüss). Efetuou-se uma medida da tensão interfacial a cada segundo, durante 30 segundos, pela técnica da gota pendente e pela equação de Young Laplace.

Para as duas superfícies da couve minimamente processada (parte superior e inferior das folhas), foram medidos os ângulos de contato entre as su-

Tabela 1. Concentrações dos sanitizantes a serem testados na descontaminação da superfície da couve minimamente processada (Rio Paranaíba, MG, 2011).

\begin{tabular}{lc}
\hline \multicolumn{1}{c}{ Sanitizante } & $\begin{array}{c}\text { Concentração } \\
\left(\mathrm{mg} \mathrm{L}^{-1}\right)\end{array}$ \\
\hline Hipoclorito de sódio & 100 \\
Dicloroisocianurato de sódio & 200 \\
Nanopartículas de prata & 6 \\
Nanopartículas de prata concentradas & 60 \\
\hline
\end{tabular}

perfícies e três líquidos com polaridades diferentes: água, formamida e $\alpha$-bromonaftaleno. O ângulo de contato foi determinado com o auxílio de goniômetro (Krüss, Germany). A medição do ângulo de contato foi realizada com a deposição de uma gota séssil, com volume de $2,0 \mu \mathrm{L}$, a cada segundo, durante 30 segundos consecutivos. As medidas foram realizadas à temperatura de $25^{\circ} \mathrm{C}$. Três repetições foram feitas para cada líquido, em cada superfície. A partir dos valores dos ângulos de contato, avaliou-se, qualitativamente, a hidrofobicidade de uma superfície.

Para a medição do ângulo de contato da superfície das células bacterianas, as medidas foram realizadas sobre uma camada de células das bactérias Staphylococcus aureus (ATCC 6538), Escherichia coli (ATCC 11229) e Listeria innocua (ATCC 33090), utilizando-se método descrito por Busscher et al. (1984).

Primeiramente, as espécies foram ativadas três vezes em caldo BHI, com a finalidade de obter-se uma suspensão da cultura ativa com, aproximadamente, $10^{7} \mathrm{UFC} \mathrm{mL}^{-1}$. Posteriormente, $30 \mathrm{~mL}$ da suspensão ativa foram centrifugados a $12.000 \times \mathrm{g}$, por 10 minutos, sendo, em seguida, lavados por três vezes, em tampão fosfato salino (PBS) 0,1 M. A massa celular foi ressuspendida nesse mesmo tampão, sendo depositada sobre filtro de membrana de acetato de celulose com poro de $0,45 \mu \mathrm{m}$ e $47 \mathrm{~mm}$ de diâmetro por filtração, utilizando-se pressão negativa. Foram adicionados $30 \mathrm{~mL}$ de água ultrapura no momento da filtração. Para padronizar o conteúdo de umidade, os filtros foram transferidos para placas de Petri contendo $1 \%$ de ágar (p/v) e $10 \%$ de glicerol (v/v). As membranas foram cortadas em três partes, sendo cada uma usada para medição do ângulo de contato com cada líquido diferente. As medidas de ângulos de contato foram realizadas para três líquidos com diferentes polaridades (água, formamida e $\alpha$-bromonaftaleno).

Para o cálculo da variação da energia de interação hidrofóbica, aplicou-se a teoria dos componentes de tensão interfacial (Van Oss 1994). Após as aproximações das equações envolvidas na teoria, a energia da superfície $\left(\gamma_{s}\right)$, seja ela da bactéria ou da couve, resultou da combinação de três contribuições:

$$
\gamma_{s}=\gamma_{s}^{L W}+\left(\gamma_{s}^{+} \gamma_{s}^{-}\right)^{1 / 2}
$$

em que $\gamma_{s}^{L W}$ representa o componente da interação de Lifshit-Van der Waals, $\gamma_{s}^{+}$a interação de ácido de Lewis e $\gamma_{s}^{-}$o componente da interação da base de Lewis. Aplicando-se uma gota de um líquido no 
equilíbrio com a superfície, os componentes $\gamma_{s}^{L W}, \gamma_{s}^{+}$ e $\gamma_{s}^{-}$foram calculados utilizando-se as medidas do ângulo de contato:

$\gamma_{l}^{\text {TOT }}(1+\cos \theta)=2 \sqrt{\gamma_{s}^{L W}} \gamma_{l}^{L W}+2 \sqrt{\gamma_{s}^{-}} \gamma_{l}^{+}+2 \sqrt{ } \gamma_{s}^{+} \gamma_{l}^{-}$

em que $\gamma_{l}^{\text {TOT }}$ é a tensão superficial do líquido usado na medida, $\theta$ o ângulo de contato e $s$ e $l$ a superfície e o líquido, respectivamente.

Para determinar esses componentes da energia livre da superfície $\left(\gamma_{s}^{L W}\right.$ e os parâmetros $\gamma_{s}^{+} \mathrm{e} \gamma_{s}^{-}$de uma superfície), foi medido o ângulo de contato de, pelo menos, três líquidos com conhecidos componentes de tensão interfacial $\left(\gamma_{L}^{L W}, \gamma_{L}^{+}\right.$e $\left.\gamma_{L}^{-}\right)$(Tabela 2).

A variação da energia livre de adesão $\left(\Delta \mathrm{G}_{\text {adesão }}\right)$ foi calculada com base nas medidas do ângulo de contato e nos valores dos componentes das tensões interfaciais, obtendo-se valores para $\Delta G_{b l s}{ }^{L W}$ e $\Delta G_{b l s}{ }^{A B}$. Após a determinação das tensões interfaciais para cada superfície [bactéria/líquido $(b l)$ e couve/líquido $(s l)$ ] e a interação entre as entidades $(b l s)$, aplicou-se a equação de Van Oss (1994):

$$
\Delta \mathrm{G}_{\text {adesão }}=\Delta G_{b l s}{ }^{L W}+\Delta G_{b l s}^{A B}
$$

em que $\Delta G^{L W}$ é a variação da energia de interação de Lifshitz-Van der Waals e $\Delta G^{A B}$ a variação da energia de interação de ácido e base de Lewis.

$\mathrm{O}$ valor de $\Delta \mathrm{G}_{\text {adesão }}$ permite fazer uma avaliação termodinâmica do processo de adesão entre as bactérias e a superfície da couve minimamente processada, sendo essa termodinamicamente favorável quando $\Delta \mathrm{G}_{\text {ades̃o }}<0$ e, ao contrário, desfavorável quando $\Delta \mathrm{G}_{\text {adesão }}>0$. Dessa forma, pode-se predizer se a adesão de determinada bactéria em uma superfície é termodinamicamente favorável ou não.

A couve apresenta, em sua estrutura, fissuras que são capazes de proteger os micro-organismos da ação química dos sanitizantes, favorecendo, desse modo, a adesão microbiana e a possível formação de biofilmes.

Em uma amostra de couve, foi inoculada a concentração de $10^{7} \mathrm{UFC}_{\mathrm{mL}^{-1}}$ de E. coli $\mathrm{O} 157: \mathrm{H} 7$,

Tabela 2. Componentes da tensão interfacial de líquidos de diferentes polaridades, a $25{ }^{\circ} \mathrm{C}$ (Rio Paranaíba, MG, 2011).

\begin{tabular}{lccrr}
\hline \multirow{2}{*}{\multicolumn{1}{c}{ Líquido }} & \multicolumn{4}{c}{ Tensão interfacial $\left(\mathrm{mJ} \mathrm{m}^{-2}\right)$} \\
\cline { 2 - 5 } & $\gamma_{l}{ }^{\text {OOT }}$ & $\gamma_{l}{ }^{\mathrm{LW}}$ & \multicolumn{1}{c}{$\gamma_{l}{ }^{+}$} & \multicolumn{1}{c}{$\gamma_{l}{ }^{-}$} \\
\hline Alfa-bromonaftaleno (B) & 44,40 & 44,40 & 0,00 & 0,00 \\
Água (A) & 72,80 & 21,80 & 25,50 & 25,50 \\
Formamida (F) & 58,00 & 39,00 & 2,28 & 39,60 \\
\hline
\end{tabular}

patógeno de interesse em alimentos, e incubada a $7^{\circ} \mathrm{C}$, por 24 horas. Em seguida, as amostras foram retiradas da suspensão do micro-organismo teste e lavadas com água destilada esterilizada, para retirada de células planctônicas. As amostras foram imersas em soluções de sanitizante (Tabela 1) por 15 minutos. As células de $E$. coli não removidas pelo sanitizante foram quantificadas. Realizou-se, também, um procedimento controle, utilizando-se somente água destilada esterilizada para a remoção de bactérias.

Amostras de $25 \mathrm{~g}$ de couve minimamente processada foram embaladas separadamente e armazenadas a $5^{\circ} \mathrm{C}$, durante 9 dias, para se fazer um estudo da evolução da contagem microbiana, em função do antimicrobiano utilizado na etapa de sanitização. A cada três dias, a partir do tempo zero, uma amostra de couve representativa de cada antimicrobiano aplicado no processamento foi submetida à determinação de mesófilos aeróbios, pela técnica de plaqueamento por profundidade, utilizando-se o ágar padrão para contagem. Os procedimentos empregados nessa etapa do trabalho foram realizados de acordo com a metodologia da American Public Health Association (APHA 1992).

Os experimentos de microbiologia foram conduzidos em delineamento inteiramente casualizado, com três repetições (biológicas) e em duplicata (réplica técnica). Os dados foram analisados por meio da análise de variância (teste F), a 5 \%, e, uma vez constatado efeito significativo do tratamento, aplicou-se, então, o teste Tukey (5\%). Todas as análises foram realizadas no programa estatístico SAS, versão 9.1.

\section{RESULTADOS E DISCUSSÃO}

A medida do ângulo de contato de uma superfície com a água é um parâmetro qualitativo da hidrofobicidade. Considera-se uma superfície como hidrofilica quando o ângulo de contato é inferior a $65^{\circ}$. Já uma superfície será hidrofóbica quando o ângulo medido for maior que $65^{\circ}$ (Vogler 1998). As superfícies na parte superior e inferior da couve são hidrofóbicas, com valores medidos de $100,4^{\circ} \mathrm{e}$ $90,4^{\circ}$, respectivamente (Tabela 3 ).

$\mathrm{O}$ parâmetro $\Delta \mathrm{G}^{\mathrm{TOT}}$ expressa a variação de energia livre associada à atração polar entre as moléculas das duas superfícies. Quando a energia livre de interação é repulsiva, isto é, o $\Delta \mathrm{G}^{\mathrm{TOT}}$ é positivo, as superfícies são ditas hidrofílicas. Quanto mais negativo o valor de $\Delta \mathrm{G}^{\mathrm{TOT}}$, mais hidrofóbicas são 
as superfícies. Por outro lado, quanto mais positivo o valor de $\Delta \mathrm{G}^{\mathrm{TOT}}$, mais hidrofílica é a superfície (Bayoudh et al. 2006).

Na Tabela 4, observa-se, pela medida da variação da energia livre total de interação $\left(\Delta \mathrm{G}^{\mathrm{TOT}}\right)$, que as superfícies da couve também foram consideradas hidrofóbicas, uma vez que os valores obtidos foram negativos $\left(-76,712 \mathrm{~mJ} \mathrm{~m}^{-2} \mathrm{e}-73,605 \mathrm{~mJ} \mathrm{~m}^{-2}\right)$.

As análises qualitativas e quantitativas também foram realizadas para as superfícies bacterianas e observou-se que, pelos dois parâmetros, todas as estirpes foram consideradas hidrofílicas, uma vez que apresentaram valores de ângulo de contato com a água inferiores a $65^{\circ}$ e valores positivos de energia livre total de interação (Tabelas 5 e 6).

A hidrofilicidade indica que as moléculas na interface, na superfície bacteriana, interagem mais com as moléculas de água, quando comparadas à interação que ocorre entre as mesmas. A termodinâmica da superfície bacteriana resulta de sua físico-química, que é controlada por componentes macromoleculares, incluindo os lipopolissacarídeos, proteínas, exopolímeros e apêndices celulares, que variam em quantidade, dependendo das condições de crescimento e de estirpe para estirpe (Strevett \& Chen 2003).

Como todo sistema, na natureza, a interação micro-organismo e superfície também procede em direção à diminuição da energia livre. A adesão do micro-organismo ocorrerá se a energia for negativa $\left(\Delta \mathrm{G}^{\text {TOT }}<0\right)$. Por outro lado, a adesão será termodi-

Tabela 3. Valores dos ângulos de contato entre as superfícies da couve com a água, formamida e $\alpha$-bromonaftaleno, medidos a $20{ }^{\circ} \mathrm{C}$ (Rio Paranaíba, $\mathrm{MG}, 2011$ ).

\begin{tabular}{|c|c|c|c|}
\hline Superfícies & Água & Formamida & $\alpha$-brol \\
\hline $\begin{array}{l}\text { Superfície couve } \\
\text { parte de cima }\end{array}$ & $100,4 \pm 2,1$ & $76,8 \pm 1,4$ & $25,1 \pm 0,6$ \\
\hline $\begin{array}{l}\text { Superfície couve } \\
\text { parte de baixo }\end{array}$ & $90,4 \pm 1,2$ & $78,7 \pm 1,3$ & $39,3 \pm 0,6$ \\
\hline
\end{tabular}

Tabela 4. Valores dos componentes apolares $\left(\Delta \mathrm{G}_{\text {sas }}{ }^{\mathrm{LW}}\right)$ e polares $\left(\Delta \mathrm{G}_{\text {sas }}{ }^{\mathrm{AB}}\right)$ da variação da energia livre total de interação das superfícies de couve (Rio Paranaíba, MG, 2011).

\begin{tabular}{lccc}
\hline \multirow{2}{*}{ Superfícies } & $\Delta \mathrm{G}_{\mathrm{sas}}{ }^{\mathrm{LW}}$ & $\Delta \mathrm{G}_{\mathrm{sas}}{ }^{\mathrm{AB}}$ & $\Delta \mathrm{G}_{\mathrm{sas}}{ }^{\text {тот }}$ \\
\cline { 2 - 4 } & \multicolumn{3}{c}{$\mathrm{mJ} \mathrm{m}^{-2}$} \\
\hline Superfície couve parte de cima & $-5,643$ & $-71,070$ & $-76,712$ \\
Superfície couve parte de baixo & $-3,079$ & $-70,526$ & $-73,605$ \\
\hline
\end{tabular}

namicamente desfavorável se positiva $\left(\Delta \mathrm{G}^{\mathrm{TOT}}>0\right)$. A adesão é termodinamicamente favorável para todas as estirpes estudadas e superfícies de couve, sendo mais favorável para as células vegetativas $S$. aureus e L. Innocua (Tabela 7).

Torna-se clara a necessidade de uma sanitização eficiente da superfície da couve antes do seu processamento, visto que a adesão de diferentes bactérias é favorável, nesse alimento. É importante enfatizar que o processo de adesão não é explicado apenas pelo aspecto termodinâmico, pois outros fatores microbiológicos podem interferir no processo. Muitas vezes, a presença de apêndices celulares é capaz de se sobrepor às forças repulsivas atuantes e promover o contato físico, iniciando um processo de adesão bacteriano. Araújo et al. (2009) constataram que a adesão de uma estirpe de $B$. cereus, isolada de uma planta de laticínios em superfície de aço inoxidável, granito e vidro, foi afetada pela hidrofobicidade, sendo maior no aço inoxidável e granito, que apresentaram características hidrofóbicas.

As nanopartículas de prata, tanto na concentração de $6 \mathrm{mg} \mathrm{L}^{-1}$ quanto de $60 \mathrm{mg} \mathrm{L}^{-1}$, foram os agentes que promoveram maior descontaminação da superfície, resultando em redução de três ciclos logarítmicos, em comparação ao controle (água). É preconizado que três reduções decimais (RD) (ou 99,9 \% de redução) são necessárias para se considerar uma solução de sanitizante eficiente para a remoção de células aderidas (Andrade 2008).

Tabela 5. Valores dos ângulos de contato entre diferentes superfícies bacterianas e água, formamida e $\alpha$-bromonaftaleno (Rio Paranaíba, MG, 2011).

\begin{tabular}{lrcc}
\hline \multirow{2}{*}{ Bactérias } & \multicolumn{1}{c}{ Água } & Formamida & $\alpha$-bromonaftaleno \\
\cline { 2 - 4 } & & ${ }^{\circ}$ & \\
\hline S. aureus & $22,40 \pm 0,5$ & $41,90 \pm 2,4$ & $44,03 \pm 1,2$ \\
E. coli & $16,53 \pm 0,6$ & $22,30 \pm 0,5$ & $52,07 \pm 2,7$ \\
L. innocua & $23,20 \pm 0,3$ & $16,77 \pm 0,4$ & $44,47 \pm 1,4$ \\
\hline
\end{tabular}

Tabela 6. Valores dos componentes apolares $\left(\Delta \mathrm{G}_{\mathrm{sas}}{ }^{\mathrm{LW}}\right)$ e polares $\left(\Delta \mathrm{G}_{\mathrm{sas}}{ }^{\mathrm{AB}}\right)$ da variação da energia livre total de interação das superfícies bacterianas (Rio Paranaíba, MG, 2011).

\begin{tabular}{lccc}
\hline \multirow{2}{*}{ Bactérias } & $\Delta \mathrm{G}_{\mathrm{sas}}^{\mathrm{LW}}$ & $\Delta \mathrm{G}_{\mathrm{sas}}^{\mathrm{AB}}$ & $\Delta \mathrm{G}_{\mathrm{sas}}^{\mathrm{TOT}}$ \\
\cline { 2 - 4 } & \multicolumn{3}{c}{$\mathrm{mJ} \mathrm{m}^{-2}$} \\
\hline S. aureus & $-2,239$ & 58,646 & 56,407 \\
E. coli & $-1,010$ & 30,807 & 29,797 \\
L. innocua & $-2,164$ & 24,027 & 21,863 \\
\hline
\end{tabular}


Tabela 7. Variação da energia livre de adesão entre diferentes espécies e superfícies de couve (Rio Paranaíba, MG, 2011).

\begin{tabular}{lccc}
\hline \multirow{2}{*}{ Espécie bacteriana/ superfície } & \multicolumn{3}{c}{ Energia livre de adesão $\left(\mathrm{mJ} \mathrm{m}^{-2}\right)$} \\
\cline { 2 - 4 } & $\Delta \mathrm{G}_{\mathrm{bls}}{ }^{\mathrm{LW}}$ & $\Delta \mathrm{G}_{\mathrm{bls}} \mathrm{AB}_{\mathrm{s}}$ & $\Delta \mathrm{G}_{\text {adesão }}$ \\
\hline S. aureus/ couve parte de cima & $-3,5548$ & $-7,2138$ & $-10,7686$ \\
S. aureus/ couve parte de baixo & $-2,6262$ & $-8,2382$ & $-10,8644$ \\
E. coli/ couve parte de cima & $-2,3875$ & $-1,9522$ & $-4,3398$ \\
E. coli/ couve parte de baixo & $-1,7638$ & $-2,6932$ & $-4,4570$ \\
L. innocua/ couve parte de cima & $-3,4949$ & $-7,2608$ & $-10,7557$ \\
L. innocua/ couve parte de baixo & $-2,5819$ & $-7,9279$ & $-10,5098$ \\
\hline
\end{tabular}

Pode-se afirmar que a sanitização com nanopartículas de prata não variou, em razão da concentração testada, pelo teste Tukey $(\mathrm{p}<0,05)$ (Tabela 8). Além disso, percebeu-se que houve diferença significativa entre os diferentes tipos de sanitizantes avaliados e o controle. $\mathrm{O}$ hipoclorito de sódio, na concentração de $100 \mathrm{mg} \mathrm{L}^{-1}$, não diferiu significativamente do dicloroisocianurato de sódio a $200 \mathrm{mg} \mathrm{L}^{-1}$, na inativação de E. coli.

Kong \& Jang (2008) compararam as propriedades antibacterianas de nanofibras de polimetilmetacrilato (PMMA) contendo nanopartículas com sulfadiazina de prata e $\mathrm{AgNO}_{3}$, na mesma concentração de prata, contra $E$. coli e $S$. aureus. As nanofibras proporcionaram maior taxa de morte. Sulfadiazina

Tabela 8. Log UFC g ${ }^{-1}$ de células vegetativas de Escherichia coli aderidas à superfície da couve, após exposição a diferentes antimicrobianos (Rio Paranaíba, MG, 2011).

\begin{tabular}{lcc}
\hline \multicolumn{1}{c}{ Antimicrobianos } & Log UFC g ${ }^{-1}$ & $\begin{array}{c}\text { Reduções } \\
\text { decimais }\end{array}$ \\
\hline Água (controle) & $5,86^{\text {a }}$ & - \\
Hipoclorito de sódio $100 \mathrm{mg} \mathrm{L}^{-1}$ & $4,23^{\mathrm{b}}$ & 1,63 \\
Dicloisocianurato de sódio $200 \mathrm{mg} \mathrm{L}^{-1}$ & $4,55^{\mathrm{b}}$ & 1,31 \\
Nanopartículas de prata $6 \mathrm{mg} \mathrm{L}^{-1}$ & $2,70^{\mathrm{c}}$ & 3,16 \\
Nanopartículas de prata $60 \mathrm{mg} \mathrm{L}^{-1}$ & $2,70^{\mathrm{c}}$ & 3,16 \\
\hline
\end{tabular}

Médias seguidas pela mesma letra, na mesma coluna, não diferem entre si, pelo teste Tukey $(\mathrm{p}<0,05)$. de prata e $\mathrm{AgNO}_{3}$ apresentaram propriedade antimicrobiana por liberação de íons de prata. Quando os íons de prata entraram em contato com a bactéria, precipitados pretos foram formados via redução do íon ou formação de sal. Os precipitados comprometeram a eficiência antimicrobiana.

As nanopartículas de prata, por apresentarem escala nanométrica, podem ter a capacidade de alcançar os sítios de colonização microbianos, que, muitas vezes, estão em espaços intercelulares ou fissuras presentes em superfícies. O efeito bactericida é influenciado pelas dimensões da partícula, tendo as menores partículas os melhores efeitos (Shahverdi et al. 2007).

Em cada tempo avaliado, durante a vida útil da couve minimamente processada, os sanitizantes testados diferiram do controle, pelo teste Tukey, a $5 \%$ (Tabela 9). Constatou-se, também, que não houve diferença estatística entre os tratamentos com hipoclorito de sódio e diclorisocianurato de sódio, em todos os tempos estudados.

No presente estudo, observou-se que as nanopartículas de prata apresentaram resultados satisfatórios na descontaminação da couve minimamente processada, quando comparadas ao controle (água), com diferenças significativas nas reduções decimais, sendo essas acima de dois ciclos logarítmicos, para ambas as concentrações $\left(6 \mathrm{mg} \mathrm{L}^{-1}\right.$ e $\left.60 \mathrm{mg} \mathrm{L}^{-1}\right)$. As

Tabela 9. Resultados das contagens de mesófilos aeróbios ( $\left.\log \mathrm{UFC} \mathrm{g}^{-1}\right)$ para amostras de couve minimamente processadas, sanitizadas com diferentes agentes antimicrobianos e armazenadas a $5{ }^{\circ} \mathrm{C}$, durante 9 dias (Rio Paranaíba, MG, 2011).

\begin{tabular}{lllll}
\hline \multicolumn{1}{c}{ Antimicrobianos } & T0 & T1 & T2 & T3 \\
\hline Água (controle) & $4,09^{\mathrm{a}}$ & $4,13^{\mathrm{a}}$ & $4,23^{\mathrm{a}}$ & $4,29^{\mathrm{a}}$ \\
Hipoclorito de sódio $100 \mathrm{mg} \mathrm{L}$ & $2,90^{\mathrm{b}}$ & $2,99^{\mathrm{b}}$ & $3,08^{\mathrm{b}}$ & $3,12^{\mathrm{b}}$ \\
Dicloisocianurato de sódio 200 mg L-1 & $2,82^{\mathrm{b}}$ & $3,06^{\mathrm{b}}$ & $3,10^{\mathrm{b}}$ & $3,26^{\mathrm{b}}$ \\
Nanopartículas de prata $6 \mathrm{mg} \mathrm{L}^{-1}$ & $1,74^{\mathrm{c}}$ & $1,84^{\mathrm{c}}$ & $1,87^{\mathrm{c}}$ & $1,88^{\mathrm{c}}$ \\
Nanopartículas de prata $60 \mathrm{mg} \mathrm{L}^{-1}$ & $1,65^{\mathrm{c}}$ & $1,69^{\mathrm{c}}$ & $1,72^{\mathrm{c}}$ & $1,77^{\mathrm{c}}$ \\
\hline
\end{tabular}

Médias seguidas pela mesma letra, na mesma coluna, não diferem entre si, pelo teste Tukey $(\mathrm{p}<0,05)$. T0: tempo zero; T1: três dias de estocagem; T2: seis dias de estocagem; T3: nove dias de estocagem. 
nanopartículas de prata também diferiram dos demais sanitizantes avaliados, apresentando redução decimal mais significativa. Os sanitizantes comumente utilizados na sanitização de produtos minimamente processados apresentam menor eficiência, quando comparados às nanopartículas de prata.

A qualidade microbiológica dos alimentos minimamente processados está relacionada à presença de micro-organismos deteriorantes, que irão influenciar nas alterações sensoriais do produto, durante a sua vida útil. Dessa forma, torna-se de extrema importância a escolha do agente sanitizante a ser empregado durante o processamento do alimento.

Não existem, na legislação brasileira, padrões microbiológicos para os produtos minimamente processados. Portanto, os padrões utilizados são aqueles que mais se aproximam de tais alimentos, ou seja, os aplicáveis para frutas frescas preparadas, constantes na legislação vigente (Brasil 2001). Já a vida útil do produto pode ser estabelecida pelo controle de qualidade do fabricante.

Não há dúvidas sobre a importância de uma sanitização eficiente, durante o processo de produção de alimentos minimamente processados. Pinheiro et al. (2005) analisaram 100 amostras de alimentos minimamente processados, comercializados em supermercados da cidade de Fortaleza, e observaram que as condições higiênico-sanitárias de frutas e hortaliças minimamente processadas precisam ser melhoradas, uma vez que os resultados (em log UFC g ${ }^{-1}$ ) apontaram 25 amostras contaminadas com Salmonella sp. e 28 apresentavam coliformes totais superiores a 5,0 x $10^{2} \mathrm{NMP} \mathrm{g}^{-1}$, indicando que 43 amostras estavam impróprias para o consumo humano.

São José \& Medeiros (2013) avaliaram a aplicação de ultrassom associado ou não ao dicloroisocianurato de sódio, na etapa de sanitização de tomates do tipo cereja. O tratamento com ultrassom combinado à solução de dicloisocianurato de sódio (200 ppm) e o procedimento com aplicação inicial de ultrassom, seguido de imersão em solução do composto clorado, foram os que promoveram as maiores reduções na microbiota inicial de mesófilos aeróbios, sendo as reduções decimais obtidas de 2,11 e 2,70 ciclos logarítmicos, respectivamente.

Dessa forma, as nanopartículas de prata podem ser consideradas uma alternativa promissora para a sanitização de superfícies de hortaliças minimamente processadas, por apresentarem significativa eficiência como agentes antimicrobianos, desde que estudos to- xicológicos sejam realizados, no futuro, para garantir a segurança do consumidor.

\section{CONCLUSÕES}

1. As nanopartículas de prata promovem reduções decimais significativas (acima de três ciclos logarítmicos) na população de $E$. coli inoculada.

2. As nanopartículas de prata são eficientes na redução da contagem de mesófilos aeróbios em couve minimamente processada, quando comparadas ao tradicional tratamento com hipoclorito de sódio a $100 \mathrm{mg} \mathrm{L}^{-1}$.

3. A superfície da couve apresenta características hidrofóbicas que podem propiciar a adesão termodinamicamente favorável para $S$. aureus, E. coli e L. innocua.

\section{REFERÊNCIAS}

ABADIAS, M. et al. Microbiological quality of fresh, minimally-processed fruit and vegetables, and sprouts from retail establishments. International Journal of Food Microbiology, Amsterdam, v. 123, n. 1-2, p. 121-129, 2008.

AMERICAN PUBLIC HEALTH ASSOCIATION (APHA). Compendium of methods for microbiological examination of foods. 3. ed. Washington, DC: APHA, 1992.

ANDRADE, N. J. Higiene na indústria de alimentos: avaliação e controle da adesão e formação de biofilmes bacterianos. São Paulo: Varela, 2008.

ARAÚJO, E. A. et al. Gibbs free energy of adhesion of Bacillus cereus isolated from dairy plants on different food processing surfaces evaluated by the hydrophobicity. International Journal of Food Science \& Technology, Oxford, v. 44, n. 12, p. 2519-2525, 2009.

ARTÉS, F.; GÓMEZ, P. A.; ARTÉS-HERNÁNDEZ, F. Physical, physiological and microbial deterioration of minimally fresh processed fruits and vegetables. Food Science and Technology International, London, v. 13, n. 3, p. 177-188, 2007.

BAYOUDH, S. et al. Quantification of the adhesion free energy between bacteria and hydrophobic and hydrophilic substrata. Materials Science \& Engineering, Lausanne, v. 26, n. 2-3, p. 300-305, 2006.

BERNI NETO, E. A.; RIBEIRO, C.; ZUCOLOTTO, V. Sintese de nanopartículas de prata para aplicação na sanitização de embalagens. São Carlos: Embrapa Instrumentação Agropecuária, 2008. (Comunicado técnico, 99). 
BRASIL. Ministério da Saúde. Agência Nacional de Vigilância Sanitária. Resolução RDC n ${ }^{\circ} 12$, de 02 de janeiro de 2001. Diário Oficial da República Federativa do Brasil, Brasília, DF, 10 jan. 2001. Seção 1, p. 45-53.

BUSSCHER, H. J. et al. Measurement of the surface free energy of bacterial cell surface and its relevance for adhesion. Applied and Environmental Microbiology, Vancouver, v. 48, n. 5, p. 980-983, 1984.

GÓMEZ-LÓPEZ, V. M. et al. Intense light pulses decontamination of minimally processed vegetables and their shelf-life. International Journal of Food Microbiology, Amsterdam, v. 103, n. 1, p. 79-89, 2005.

HEIMLER, D. et al. Polyphenol content and antioxidant activity in some species of freshly consumed salads. Journal of Agricultural and Food Chemistry, Mysore, v. 55, n. 5, p. 1724-1729, 2007.

KONG, H.; JANG, J. Antibacterial properties of novel poly (methyl methacrylate) nanofiber containing silver nanoparticles. Langmuir, Washington, DC, v. 24, n. 5, p. 2051-2056, 2008.

MORETTI, C. L. Manual de processamento mínimo de frutas e hortaliças. Brasília, DF: Embrapa Hortaliças, 2007.

MORETTI, C. L.; MAROUELLI, W. A.; SILVA, W. L. C. Respiratory activity and browning of minimally processed sweet potatoes. Horticultura Brasileira, Brasília, DF, v. 20, n. 3, p. 497-500, 2002.

MORONES, J. R. et al. The bactericidal effect of silver nanoparticles. Nanotechnology, Bristol, v. 16, n. 10, p. 2346-2353, 2005.
PINHEIRO, N. M. S. et al. Avaliação da qualidade microbiológica de frutos minimamente processados comercializados em supermercados de Fortaleza. Revista Brasileira de Fruticultura, Jaboticabal, v. 27, n. 1, p. 154155, 2005.

SÃO JOSÉ, J. F. B.; MEDEIROS, H. S. Uso de ultrassom associado ou não ao dicloisocianurato de sódio na sanitização de tomate cereja (Lycopersicon esculentum var. cerasiforme). Revista do Instituto Adolfo Lutz, São Paulo, v. 72, n. 3, p. 244-248, 2013.

SHAHVERDI A. R. et al. Synthesis and effect of silver nanoparticles on the antibacterial activity of different antibiotics against Staphylococcus aureus and Escherichia coli. Nanomedicine, London, v. 3, n. 2, p. 168-171, 2007.

SREBERNICH, S. M. Utilização do dióxido de cloro e do ácido peracético como substitutos do hipoclorito de sódio na sanitização do cheiro-verde minimamente processado. Ciência e Tecnologia de Alimentos, Campinas, v. 27, n. 4, p. 744-750, 2007.

StREVETT, K. A.; CHEN, G. Microbial surface thermodynamics and applications. Research Microbiology, Paris, v. 154, n. 5, p. 329-335, 2003.

VAN LOOSDRECHT, M. et al. Hydrophobic and electrostatic parameters in bacterial adhesion. Aquatic Sciences, Ottawa, v. 51, n. 1, p. 103-114, 1990.

VAN OSS, C. L. Interfacial forces in aqueous media. New York: Marcel Dekker, 1994.

VOGLER, E. A. Structure and reactivity of water at biomaterial surfaces. Advances in Colloid Interface Science, Melbourne, v. 74, n. 1-3, p. 69-117, 1998. 